\title{
XIX. Examination of Babingtonite
}

\section{Robert D. Thomson M.D.}

To cite this article: Robert D. Thomson M.D. (1845) XIX. Examination of Babingtonite, Philosophical Magazine Series 3, 27:178, 123-125, DOI: $10.1080 / 14786444508645236$

To link to this article: http://dx.doi.org/10.1080/14786444508645236

$$
\text { 册 Published online: } 30 \text { Apr } 2009 .
$$

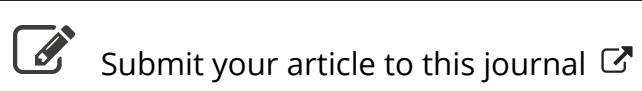

\footnotetext{
Џll Article views: 2
}

Q View related articles $\sqsubset$ 
of sulphuretted hydrogen. The highly soluble hyposulphite of lime may then be dissolved out by little more than an equal weight of cold water. The solution may be evaporated at $120^{\circ}$, and the hyposulphite of lime crystallized out; or, the solution, by adding carbonate of soda, converted into hyposulphite of soda, which is a more stable salt, may be evaporated at a higher temperature, and crystallizes more easily.

From the refuse-lime, one-sixth of its weight of crystallized hyposulphite of lime has been obtained in a state of purity by a single crystallization. When the gas is washed with sulphuric acid to remove ammonia, before being conducted into the lime-purifier, it yields the refuse-lime more suitable for this purpose. The preparation of the hyposulphites in quantity is becoming the more important, as besides their use in electro-plating and photography, they are likely to be applied largely to the extraction of chloride and bromide of silver from silver ores.

XIX. Examination of Babingtonite. By RoBERT D. Thomson, M.D., Lecturer on Practical Chemistry in the University of Glasgow*. $S_{\text {midomatischer Korazit (Breithaupt). }}^{Y N O N Y M S \text {-Axotomous Augite spar (Haidinger); he- }}$

History.-The name Babingtonite was given in 1824, by M. Levy, to a mineral occurring crystallized on felspar from Arendal in Norway, in honour of Dr. Babington, one of the founders of the Geological Society of Londont. Hitherto this mineral has been of such rare occurrence, that no analysis of it has been made. A specimen having lately come into my possession, I have taken the opportunity of subjecting it to a careful examination.

Crystalline Form.-The crystals examined appear to agree exactly with those described by Levy. They occur distributed over the surface of albite and associated with dark green amphibole. The crystals are sometimes six-sided, at other times eight-sided, doubly oblique prisms.

The colour of the crystals is black, and the lustre splendent and vitreous.

The hardness is 5.25 .

The specific gravity is 3.355 . It is stated by Breithaupt to be 3.406 , a very close approximation; and in Alger's edition of Phillips's Mineralogy, the specific gravity is given as 3.5

* Communicated by the Author.

+ Annals of Philosophy, Second Series, vol. vii. p. 275. 


\section{Dr. R. D. Thomson's Examinalion of Babingtonite.}

without any authority. Kobell fixes it at $3 \cdot 4$, on what authority is not mentioned.

Before the blowpipe the crystals fuse per se into a black enamel.

With carbonate of soda they fuse into a green opake bead in the reducing flame.

With borax in excess a clear pale yellow bead becoming violet, and with microcosmic salt in excess a clear pale amber bead are formed. These results are similar to those obtained by Mr. Children, and his conclusions respecting the nature of the constituents of the mineral, by testing, are corroborated by analysis.

The following analysis was made with the careful assistance of my friend and pupil, William Parry, Esq., late of the 4th King's Own Regiment.

20.87 grains lost by a red heat 0.26 grs. water,

$19 \cdot 62$ grains gave $9 \cdot 42$ grs. silica,

3.38 ... protoxide of iron,

$2 \cdot 17 \ldots$ red oxide of manganese,

or

2.02 ... protoxide of manganese,

1.29 ... alumina,

$5 \cdot 34$... carbonate of lime,

or

2.93 ... lime,

$0.44 . .$. magnesia.

These numbers correspond with the following per-centage composition :-

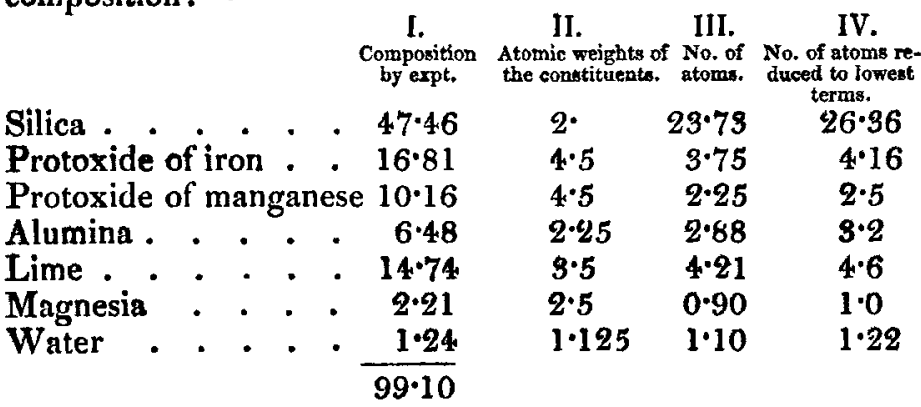

It is necessary to observe that the manganese contained a minute portion of iron.

The first column gives the results of experiment; the second the atomic weights of the constituents; the third column is the product of the division of the first by the second column; and the fourth exhibits the product of the division of the numbers in the third column by the lowest term in that column.

The following Table expresses the theoretical composition 
of the mineral as deduced from the third and fourth columns of the preceding table:-

By calculation. No, of atoms. Atomic weight.

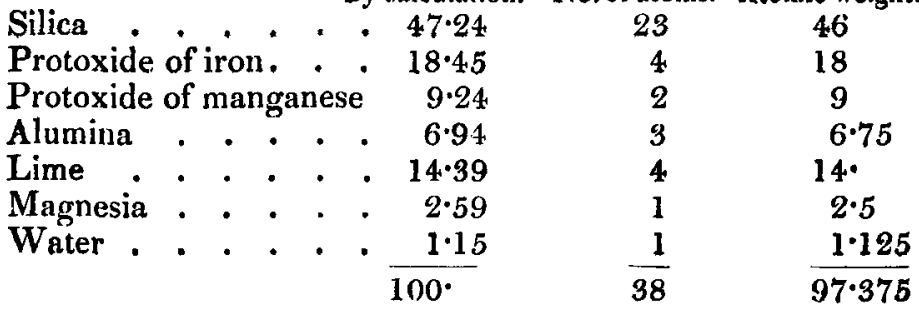

The formula to express the composition of babingtonite, as deduced from these calculations, is as follows:-

$\mathrm{MgO} \mathrm{SiO},+4 \mathrm{CaO} \mathrm{SiO}+4 \mathrm{FeO}(\mathrm{SiO})_{2}+2 \mathrm{MnO}(\mathrm{SiO})_{2}+3 \mathrm{AlO}(\mathrm{SiO})_{2}+\mathrm{HO}$; or it consists of two simple silicates and three bisilicates.

Babingtonite agrees with the amphibole class in possessing a complicated constitution. It contains nearly the same amount of silica, but much less magnesia and a greater amount of manganese. Its specific gravity is also much higher than that of amphibole. My analysis approaches one by Bonsdorff, of a black hornblende from Nordmark and Pargas, the magnesia being replaced by manganese in babingtonite.

XX. On the Resolution of Equations of the Fifth Degree. By James Cockle, Master of Arts, of Trinity College, Cambridge; of the Middle Temple, Special Pleader*.

1. $\mathrm{N}$ the equation of the fifth degree in $y$,

$$
y^{5}+p_{1} y^{4}+p_{2} y^{3}+p_{3} y^{2}+p_{4} y+p_{5}=0 . .
$$

Let

$$
p_{3}=\frac{p_{1}}{5}\left(\frac{2 p_{1}{ }^{2}}{5}+3 \mathrm{~A}\right) \text {. }
$$

and

$$
p_{4}=\frac{p_{1}}{5^{2}}\left(\frac{p_{1}^{3}}{5}+3 p_{1} \mathrm{~A}+\mathbf{A}^{2}\right), \quad \text {. . . }
$$

where

$$
\mathrm{A}=p_{2}-\frac{2 p_{1}^{2}}{5} ; \quad \cdot . \cdot . \cdot . \quad \text {. }
$$

then, if $v-\frac{p_{1}}{5}$ be substituted for $y$ in (1.), we obtain an equation in $v$ of the form of De Moivre. Denoting by $x$ the root of the general equation of the fifth degree, let

$y=\Sigma_{Q}\left(\Lambda^{\prime} x^{\lambda^{\prime}}\right)+\Sigma_{4}\left(\mathbf{M}^{\prime} x^{\mu^{\prime}}\right)+\mathrm{N}^{\prime} x^{\gamma^{\prime}}+\mathrm{P}^{\prime} x^{\tau^{\prime}}+\mathrm{Q}^{\prime} x^{\boldsymbol{x}^{\prime}}+\Sigma_{2}\left(\mathrm{R}^{\prime} x^{\prime}\right)$,

the suffixes denoting the number of quantities included under each $\Sigma$, and the expression for $y$ consisting, consequently, of

* Communicated by T. S. Davies, Esq., F.R.S., F.S.A. 